\title{
Effect of Antibiotics and Carbohydrate Diet Control Instructions in Improving Glycated Hemoglobin among Type II Diabetic Patients with Periodontitis
}

\author{
Manea Musa Al-Ahmariఠ
}

\begin{abstract}
Aim: This study was aimed to assess the effect of the scaling and root planing (SRP) with or without doxycycline and received carbohydrate diet control instructions in improving glycated hemoglobin ( $\mathrm{HbA1c}$ ) among type II diabetes mellitus (DM) patients diagnosed with periodontitis. Materials and methods: Nonrandomized clinical study design was conducted among 150 patients who were referred to the specialist dental centers in Abha city, between April 2019 and March 2021. The patients were allocated into two groups. Those receiving SRP with doxycycline were classified as group A, whereas patients who received SRP alone were classified as group B. The HbA1c levels were assessed at the baseline, and 3, 6, 12, and 24 months. Statistical package for the social sciences SPSS version 26 was used. $p<0.05$ was considered statistically significant. Results: There is a statistically significant difference in $\mathrm{HbA} 1 \mathrm{c}$ level between the two groups during follow-up after 3,6, 12, and 24 months $(p<0.001, p<0.001, p<0.001$, and $p<0.001$, respectively). Moreover, the improvement in HbA1c level was significantly observed after 24 months of follow-up in group A compared to group B $(p<0.001)$ and most of this improvement was after the first 3 months of the follow-up.

Conclusion: The SRP associated with doxycycline is more effective in improving HbA1c level among type II DM patients diagnosed with periodontitis than SRP alone. Most of the improvement is seen after 3 months of the follow-up.

Clinical significance: Valuable information is provided for dental professionals about the importance of prescription of antibiotics with the periodontal treatment in improving the $\mathrm{HbA1}$ c level in type II DM patients.

Keywords: Antibiotics, Diabetes, Glycated hemoglobin, Periodontitis.

The Journal of Contemporary Dental Practice (2021): 10.5005/jp-journals-10024-3185
\end{abstract}

\section{INTRODUCTION}

Periodontal diseases are common infections that can affect the tooth-supporting structures and eventually lead to tooth loss, if left untreated. ${ }^{1,2}$ Periodontitis is affected by systemic disorders. ${ }^{3}$ Diabetes mellitus (DM) is one of the causal factors of periodontitis., ${ }^{1,3}$ Globally, DM and periodontitis are highly prevalent among the population. ${ }^{4}$ Almost $10-15 \%$ of adult healthy patients have periodontitis. However, it is reported that type II DM patients were 2.8 times more affected by periodontitis and alveolar bone loss when compared to 1.2 times among non-DM patients.

DM is one of the metabolic diseases characterized by hyperglycemia due to defects in insulin secretion, action, or both. ${ }^{4}$ It is classified into two main types. Type IDM is caused by destruction of the pancreatic b cells where insulin is produced. Defect in insulin molecules or from defective cell receptors for insulin (impaired insulin function) causes type II DM. ${ }^{4}$ In the Kingdom of Saudi Arabia (KSA), the prevalence of DM reached $14.4 \%$ in 2016 and is estimated to increase to $27.1 \%$ by 2035 . However, an estimated $40.3 \%$ of those aged 30 years and above were unaware of their disease status. ${ }^{6}$

Periodontitis is one of the complications of chronic hyperglycemic conditions, and it is more prevalent and severe in patients with DM. ${ }^{4}$ Poor glycated hemoglobin (HbA1c) in DM patients can cause a decline in polymorph nucleate leukocyte activity. It can also impair the microvascular endothelium which as a result can cause periodontal disease. DM patients with severe periodontitis are six times more likely to have poor HbA1c than patients with healthy periodontium. However, improved $\mathrm{HbA1c}$ has been suggested to reduce the severity of periodontal disease. ${ }^{5}$
Department of Periodontics and Community Dental Sciences, College of Dentistry, King Khalid University, Abha, Saudi Arabia

Corresponding Author: Manea Musa Al-Ahmari, Department of Periodontics and Community Dental Sciences, College of Dentistry, King Khalid University, Abha, Saudi Arabia, Phone: +966 540961199 , e-mail: abudanahmm@gmail.com

How to cite this article: Al-Ahmari MM. Effect of Antibiotics and Carbohydrate Diet Control Instructions in Improving Glycated Hemoglobin among Type II Diabetic Patients with Periodontitis. J Contemp Dent Pract 2021;22(10):1118-1122.

Source of support: Nil

Conflict of interest: None

Many studies have revealed that the effective periodontal treatment improves HbA1c level among type II DM patients diagnosed with periodontitis. As well as it might inhibit the development of arteriosclerosis. $^{2}$

Recently, several studies have shown the effects of periodontal treatment on $\mathrm{HbA1c}$. Some studies were reported that the $\mathrm{HbA1c}$ levels in type II DM patients who received periodontal treatment with antibiotics were reduced significantly. ${ }^{3,4,7-16}$ However, other studies by Raman et al., ${ }^{1}$ Skaleric et al., ${ }^{17}$ and Simpson et al. ${ }^{18}$ found no improvement in $\mathrm{HbA1c}$ after periodontal treatment with antibiotics. All studies have shown a discrepancy in the effectiveness of antibiotics in improving HbA1c. There was no similar study conducted in Abha city, KSA. Therefore, this study was aimed to assess the effect of the scaling and root planing (SRP) with or 
without doxycycline prescription and received carbohydrate diet control instructions in improving $\mathrm{HbA1c}$ level among type II DM patients diagnosed with periodontitis.

\section{Methodology}

\section{Ethics Approval and Consent to Participate}

This study was approved by the research and ethics committee at the authority of medical sector in Abha city. It was carried out in accordance with the Declaration of Helsinki. An official letter to conduct this study was sent to the health authorities and the specialist dental centers in Abha city. Informed consent was taken from all participants. Confidentiality of data was assured and ensured.

\section{Study Design and Population}

Nonrandomized clinical study design was conducted among the type II DM patients diagnosed with periodontitis attending to the specialist dental centers in Abha city, KSA. It was used to assess the effect of doxycycline and carbohydrate diet control instructions in improving $\mathrm{HbA1c}$ among type II DM patients diagnosed with periodontitis.

\section{Inclusion and Exclusion Criteria}

This study included all type II DM patients diagnosed with periodontitis who were referred to the specialist dental centers in Abha city, during the period between April 2019 and March 2021. Patients aged above 27 years and those who have completed all follow-up visits (at 3, 6, 12, and 24 months) were included in this study.

However, patients aged 27 years or less, who had type I DM, who are pregnant and lactating women, who had complications and systemic disease other than DM, who received antibiotics in the past 3 months, and who did not complete the follow-up period were excluded.

\section{Sample Size Calculation}

A sample size of 144 patients was estimated by $\mathrm{G}^{*}$ power software, version 3.1.9.4. based on an alpha of 0.05 , power of $80 \%$, assuming effect size 0.5 needed to detect the difference between the two groups and allocation ratio group B/group $A$ of 0.5 . To compensate for dropouts during the study period, the sample size was increased by $10 \%$ so that 159 patients were recruited and were classified into two groups: group A (100 patients) and group B (50 patients).

\section{Intervention}

The study started with a baseline survey among type II DM patients diagnosed with periodontitis. The patients were allocated into two groups according to the type of periodontal treatment. Patients who received SRP with antibiotics prescription (doxycycline $100 \mathrm{mg}$ OD for 2 weeks) and received carbohydrate diet control instructions were classified as group A. Patients who received SRP without antibiotics prescription and received carbohydrate diet control instructions were classified as group $B$.

At the baseline point (the first visit), all patients received periodontal treatment according to their allocated groups. The collected data consisted of the following variables: age, sex, smoking status, and type of periodontal treatment (SRP with or without antibiotics prescription and receiving carbohydrate diet control instructions). In addition to that, it involved variables related to the date and $\mathrm{HbA} 1 \mathrm{c}$ level at the first visit and follow-up visits at $3,6,12$, and 24 months.

\section{Data Processing and Analyses}

SPSS version 26 was used for data entry and analysis. KolmogorovSmirnov test was used to assess the data distribution. It indicates that the ages in two groups are not normal distribution $(p<0.05)$. The HbA1c in group A is not normal distribution $(p<0.05)$, whereas in group $B$ it is a normal distribution $(p>0.05)$. However, the percentage, median, and interquartile range (IQR) as quartile 1 and quartile 3 were used to describe the data and compare between the two groups. And, the mean and SD were used as an additional measure. The median and mean differences in $\mathrm{HbA} 1 \mathrm{c}$ levels between different visits for two groups were calculated. The Mann-Whitney $U$ and Chi-squared tests were used to test the significant difference between the two groups $p<0.05$ was considered statistically significant.

\section{Results}

A total of 150 type II DM patients diagnosed with periodontitis completed the study period. Group A consisted of 100 patients who received SRP with doxycycline prescription and received carbohydrate diet control instructions. The second group consisted of 50 patients who received SRP without antibiotics prescription and received carbohydrate diet control instructions (group B).

\section{Characteristics of Participants}

Table 1 shows the characteristics of subjects among groups $A$ and $B$. The median (IQR) age of patients among groups $A$ and $B$ were 54 (44 and 64) years and 55 (45 and 63) years, respectively ( $p=0.791$ ). The percentages of females were $64 \%$ and $58 \%$ among groups $A$ and $B$, respectively $(p=0.475)$. The percentage of smokers among group $A$ was $20 \%$ as compared to $34 \%$ among group $\mathrm{B}(p=0.061)$. Moreover, the median (IQR) of the baseline HbA1c level was 7.7 (6.6 and 9.0) among group A as compared to 7.8 (7.0 and 9.2) among group B. There is no statistically significant difference in baseline $\mathrm{HbA1c}$ level between groups $\mathrm{A}$ and $\mathrm{B}(p=0.232)$.

Table 1: Characteristics of the type II diabetic patients diagnosed with periodontitis

\begin{tabular}{lccc}
\hline Characteristics & $\begin{array}{c}\text { Group } A \\
(n=100)\end{array}$ & $\begin{array}{c}\text { Group B } \\
(n=50)\end{array}$ & p value \\
\hline Age-group (years) & & & \\
$\quad$ Median (IQR) & $54(44$ and 64) & $55(45$ and 63) & $0.791^{\mathrm{a}}$ \\
Mean age ( \pm SD) & $53.6(13.9)$ & $54.2(11.6)$ & \\
Sex: no. $(\%)$ & & & \\
$\quad$ Male & $36(36)$ & $21(42)$ & $0.475^{\mathrm{b}}$ \\
Female & $64(64)$ & $29(58)$ & \\
Smoking status: no. (\%) & & & \\
$\quad$ Smoker & $20(20)$ & $17(34)$ & $0.061^{\mathrm{b}}$ \\
$\quad$ Nonsmoker & $80(80)$ & $33(66)$ & \\
Baseline HbA1c level: & & & \\
Median (IQR) & $7.7(6.6$ and 9.0) & $7.8(7.0$ and 9.2) & $0.232^{\mathrm{a}}$ \\
Mean ( \pm SD) & $8.0(1.8)$ & $8.1(1.4)$ & \\
\hline
\end{tabular}

${ }^{\mathrm{a}}$ Mann-Whitney $U$ test; ${ }^{\mathrm{b}} \mathrm{Chi}$-squared test 


\section{Comparison of Glycated Hemoglobin Level between Two Groups}

Table 2 shows the comparison of the glycated hemoglobin levels during the baseline and follow-up periods between the two groups. The median (IQR) of baseline HbA1c level was 7.5 (6.6 and 10.0) in group A compared with 7.8 (7.1 and 9.2) in group B. Therefore, there is no statistically significant difference in the baseline $\mathrm{HbA1c}$ level between the two groups $(p=0.232)$. However, in the second visit (after 3 months), the median (IQR) of HbA1c level was 6.4 (6.0 and 7.2) in group $A$ as compared to 7.7 (6.9 and 8.9) in group B. In the third visit (after 6 months), the median (IQR) of HbA1c level was 6.3 (6.0 and 7.2) in group A as compared to 7.9 (6.7 and 8.9) in group B. Furthermore, in the fourth visit (after 12 months), the median (IQR) of $\mathrm{HbA1c}$ level was 6.2 (5.9 and 7.2) in group A as compared to 7.8 (6.8 and 8.8) in group B. In the last visit (after 24 months), the median (IQR) of HbA1c level was 6.1 (5.7 and 7.1) in group A as compared to 7.9 (6.7 and 8.7) in group B. In summary, there is a statistically significant difference in $\mathrm{HbA1}$ c levels between the two groups during follow-up at 3,6, 12, and 24 months ( $p<0.001, p<0.001, p<0.001$, and $p<0.001$, respectively).

\section{Comparing the Change or Improvement in Glycated Hemoglobin Level at Different Periods of Follow-up between Two Groups}

Table 3 shows the comparison of the change in $\mathrm{HbA1c}$ level at different periods of follow-up between the two groups. The median difference (IQR) in $\mathrm{HbA} 1 \mathrm{c}$ level during the period between the baseline and 24 months in group A was higher 1.2 (0.6 and 2.3) as compared to 0.3 (0.1 and 0.7$)$ in group $B$. Therefore, there is a statistically significant difference in improving $\mathrm{HbA1c}$ level during the period between the baseline and 24 months between the two groups ( $p$ <.001). Similarly, the median difference (IQR) in HbA1c level during the period between the baseline and 3 months in group A was higher 0.7 (0.5 and 2.3) as compared to 0.2 (0.1 and 0.3) in group $B$. Therefore, there is a statistically significant difference in $\mathrm{HbA1c}$ level during the period between the baseline and 3 months between the two groups $(p<0.001)$.

On the contrary, the median difference (IQR) in $\mathrm{HbA1c}$ level during the period between 3 and 6 months was 0.1 (0.0 and 0.2)

Table 2: Comparison of the glycated hemoglobin levels during the baseline and follow-up periods between the two groups

\begin{tabular}{|c|c|c|c|}
\hline Baseline & $\begin{array}{c}\text { Group A } \\
(n=100)\end{array}$ & $\begin{array}{l}\text { Group B } \\
(n=50)\end{array}$ & $p$ value \\
\hline Median (IQR) & 7.5 (6.6 and 10.0) & 7.8 (7.1 and 9.2) & 0.232 \\
\hline Mean $( \pm S D)$ & $8.0(1.8)$ & $8.1(1.4)$ & \\
\hline \multicolumn{4}{|l|}{3 months } \\
\hline Median (IQR) & 6.4 (6.0 and 7.2) & 7.7 (6.9 and 8.9) & 0.000 \\
\hline Mean $( \pm S D)$ & $6.7(1.2)$ & $7.9(1.4)$ & \\
\hline \multicolumn{4}{|l|}{6 months } \\
\hline Median (IQR) & 6.3 (6.0 and 7.2) & 7.9 (6.7 and 8.9) & 0.000 \\
\hline Mean $( \pm S D)$ & $6.6(1.2)$ & $7.8(1.3)$ & \\
\hline \multicolumn{4}{|l|}{12 months } \\
\hline Median (IQR) & 6.2 (5.9 and 7.2) & 7.8 (6.8 and 8.8) & 0.000 \\
\hline Mean $( \pm S D)$ & $6.5(1.2)$ & $7.8(1.3)$ & \\
\hline \multicolumn{4}{|l|}{24 months } \\
\hline Median (IQR) & 6.1 (5.7 and 7.1) & 7.9 (6.7 and 8.7) & 0.000 \\
\hline Mean $( \pm S D)$ & $6.4(1.2)$ & $7.7(1.3)$ & \\
\hline
\end{tabular}

${ }^{a}$ Mann-Whitney $U$ test
Table 3: Comparison of the change in glycated hemoglobin levels at different periods of follow-up between the two groups

\begin{tabular}{|c|c|c|c|}
\hline Period of follow-up & $\begin{array}{l}\text { Group A } \\
(n=100)\end{array}$ & $\begin{array}{l}\text { Group B } \\
(n=50)\end{array}$ & pvalue ${ }^{a}$ \\
\hline \multicolumn{4}{|l|}{$\begin{array}{l}\text { Change between } \\
\text { baseline and } \\
24 \text { months }\end{array}$} \\
\hline Median difference (IQR) & $1.2(0.6$ and 2.3$)$ & 0.3 (0.1 and 0.7) & 0.000 \\
\hline Mean difference $( \pm S D)$ & $1.6(1.2)$ & $0.4(0.9)$ & \\
\hline \multicolumn{4}{|l|}{$\begin{array}{l}\text { Change between } \\
\text { baseline and } 3 \text { months }\end{array}$} \\
\hline Median difference (IQR) & 0.7 (0.5 and 2.3) & 0.2 (0.1 and 0.3$)$ & 0.000 \\
\hline Mean difference $( \pm S D)$ & $1.3(1.2)$ & $0.2(0.2)$ & \\
\hline \multicolumn{4}{|l|}{$\begin{array}{l}\text { Change between } 3 \text { and } \\
6 \text { months }\end{array}$} \\
\hline Median difference (IQR) & 0.1 (0.0 and 0.2) & $0.1(0.0$ and 0.1$)$ & 0.402 \\
\hline Mean difference $( \pm S D)$ & $0.1(0.3)$ & $0.1(0.8)$ & \\
\hline \multicolumn{4}{|l|}{$\begin{array}{l}\text { Change between } 6 \text { and } \\
12 \text { months }\end{array}$} \\
\hline Median difference (IQR) & 0.1 (0.0 and 0.2$)$ & $0.0(0.0$ and 0.1$)$ & 0.043 \\
\hline Mean difference $( \pm S D)$ & $0.1(0.5)$ & $0.04(0.2)$ & \\
\hline \multicolumn{4}{|l|}{$\begin{array}{l}\text { Change between } 12 \\
\text { and } 24 \text { months }\end{array}$} \\
\hline Median difference (IQR) & $0.0(0.0$ and 0.2$)$ & $0.0(0.0$ and 0.1$)$ & 0.081 \\
\hline Mean difference $( \pm S D)$ & $0.1(0.2)$ & $0.04(0.1)$ & \\
\hline
\end{tabular}

${ }^{a}$ Mann-Whitney $U$ test

in group $A$ and 0.1 (0.0 and 0.1$)$ in group $B$. Therefore, there is no statistically significant difference in $\mathrm{HbA1c}$ level during the period between 3 and 6 months between the two groups $(p=0.402)$, whereas there is a slight statistically significant difference in $\mathrm{HbA1c}$ level between the two groups during the period from 6 to 12 months ( $p=0.043$ ). Moreover, there is no statistically significant difference in $\mathrm{HbA} 1 \mathrm{c}$ level between the two groups during the period from 12 to 24 months ( $p=0.081$ ).

\section{Discussion}

The study was aimed to assess the improvement in HbA1c levels after periodontal treatment of type II DM patients diagnosed with periodontitis. The subjects in group $A$ underwent SRP with doxycycline prescription and received carbohydrate diet control instructions, whereas the subjects in group B underwent SRP without doxycycline prescription and received carbohydrate diet control instructions. It showed that a change or improvement in $\mathrm{HbA1c}$ level was higher among group $\mathrm{A}$ than group $\mathrm{B}$, particularly after the first 3 months of follow-up.

The results of this study indicate that the ages of participants in both groups were comparable. Besides, there is no significant difference in sex and smoking status between the groups. Similarly, the baseline HbA1c level among type II DM patients diagnosed with periodontitis in both groups was comparable. Findings of our study found that the baseline $\mathrm{HbA} 1 \mathrm{c}$ level was no significant difference between groups $\mathrm{A}$ and $\mathrm{B}(p=0.232)$. This means the $\mathrm{HbA1c}$ level of type II DM patients diagnosed with periodontitis before periodontal treatment was comparable in the two groups. After follow-up for 3 , 6,12 , and 24 months of periodontal treatment, the HbA1c level was significantly reduced in group A compared to group B $(p<0.001$, $p<0.001, p<0.001$, and $p<0.001$, respectively). Regarding the overall 
change or improvement in HbA1c level after 24 months of follow-up, the results revealed that the $\mathrm{HbA1c}$ level has a significant difference between the two groups $(p<0.001)$. This means that after 24 months of follow-up, the overall $\mathrm{HbA1c}$ level was reduced by $16 \%$ among group $A$ as compared to $3.8 \%$ among group $B$, whereas after 3 months of follow-up, the change in $\mathrm{HbA1c}$ level was significantly different between the two groups ( $p<0.001$ ). The HbA1c level was reduced by $9.3 \%$ among group $A$ as compared to $2.6 \%$ among group $B$, whereas the change in $\mathrm{HbA} 1 \mathrm{c}$ level during the period between 3 and 6 months of follow-up has no significant difference between the two groups $(p<0.402)$. After that, the difference was again observed slightly during the period between 6 and 12 months of follow-up between the two groups ( $p<0.043$ ), but it disappeared during the period between 12 and 24 months $(p<0.081)$. However, most of the improvement in the overall $\mathrm{HbA1c}$ level (58\%) within group A was more when observed after 3 months of periodontal treatment as compared to 6,12 , and 24 months of follow-up. This study suggests that the improvement in $\mathrm{HbA1c}$ level is attributed to doxycycline prescription and carbohydrate diet control instructions associated with periodontal treatment for type II DM patients diagnosed with periodontitis. Katagiri et al. ${ }^{8}$ suggested that periodontal treatment with antibiotics improves $\mathrm{HbA1c}$ through the reduction of $\mathrm{C}$-reactive protein, which may relate to amelioration of insulin resistance, in type II DM patients with periodontal disease. The results of our study agree with studies conducted by Aranzazu-Moya et al., ${ }^{7}$ TsobgnyTsague et al., ${ }^{9}$ and Bharti et al. ${ }^{10}$ indicated that the periodontal treatment combined with systemic or topical antibiotics improves HbA1c in type II DM patients. Moreover, findings of three studies using doxycycline support our results; Das et al. ${ }^{11}$ reported that the adjunct of doxycycline to conventional periodontal therapy provides an additional benefit in reducing glycemic level. Al-Zahrani et al. ${ }^{13}$ revealed that the mean $\mathrm{HbA1c}$ level after treatment was significantly reduced in groups receiving SRP plus doxycycline. O'Connell et al. ${ }^{4}$ showed that a significant reduction in $\mathrm{HbA1c}$ levels was obtained, which represented a mean $10.7 \%$ improvement compared to baseline values. The SRP plus Doxy group showed a significant reduction of $1.5 \%$, which corresponded to a $13 \%$ improvement, whereas the SRP group showed a reduction of $0.9 \%$, which corresponded to only a 7\% improvement.

Concerning the follow-up for 3 months, our results are consistent with studies conducted by Rodrigues et al. ${ }^{15}$ and Grossi et al. $^{16}$ They reported that the periodontal treatment reduced the $\mathrm{HbA1c}$ values after the 3-month observation period in both groups; however, the reduction in $\mathrm{HbA1c}$ values for the group $\mathrm{B}$ (received SRP without antibiotics) was statistically significant, but not for the group A (received SRP without antibiotics) $(p<0.05)$. A study by Macedo et al. ${ }^{12}$ showed that the differences of $\mathrm{HbA} 1 \mathrm{c}$ between baseline and 3 months were greater for the group that received SRP plus antimicrobial photodynamic therapy (11.4\%) than the group that received SRP (10\%) $(0.87 \pm 0.9$ and $0.4 \pm 0.84$ respectively; $p<0.05)$. Singh et al. ${ }^{14}$ indicated that $\mathrm{HbA1c}$ values are more significantly decreased over the period of 3 months in group B (received treatment with scaling and root planing followed by systemic doxycycline) than group A (received treatment with SRP only). Qureshi et al. ${ }^{19}$ conducted a three-arm randomized controlled trial in which intervention for test group A (received SRP with metronidazole and oral hygiene instructions) and test group B (received SRP and oral hygiene instructions), but control group received oral hygiene instructions only. It revealed that significant reductions were observed in $\mathrm{HbA1c}$ in both test groups in comparison with control group $(p<0.05)$.
In contrast, findings of our study disagree with three previous studies. A study by Raman et al. ${ }^{1}$ indicated similar improvements in $\mathrm{HbA1c}$ levels, but this improvement in mean levels of both groups did not reach statistical significance. A study by Skaleric et al. ${ }^{17}$ revealed that the $\mathrm{Hb} 1 \mathrm{Ac}$ level was reduced in all patients; however, the difference between the two groups was not significant. The systemic review of published studies conducted by Simpson et al. ${ }^{18}$ showed that there was no consistent evidence that the addition of antimicrobials to SRP was of any benefit to delivering SRP alone. The disagreement between the results of previous studies and ours might be due to the discrepancy in methodology, such as randomization and design.

The main limitation of this study is the patients in the two groups were not randomly selected and allocated. Additionally, this study did not measure the inflammation markers; thus, the relation between the improvements in $\mathrm{HbA} 1 \mathrm{c}$ levels following periodontal treatment and inflammatory markers was not evaluated.

\section{Conclusion}

The periodontal treatment associated with doxycycline prescription and carbohydrate diet control instructions is more effective in improving $\mathrm{HbA1c}$ level among type II DM patients diagnosed with periodontitis than periodontal treatment with scaling and planning alone. Most of the improvement in $\mathrm{HbA1c}$ level was seen after 3 months of follow-up. A randomized clinical study is recommended to confirm that the improvement in $\mathrm{HbA} 1 \mathrm{c}$ level was attributed to doxycycline prescription associated with SRP.

\section{Clinical Significance}

The study provides valuable information for dental professionals about the importance of prescription of antibiotics with the periodontal treatment in improving the $\mathrm{HbA1c}$ level in type II DM patients.

\section{Availability of Data and Materials}

The data of the study are available from the corresponding author on reasonable request.

\section{OrCID}

Manea Musa Al-Ahmari @ https://orcid.org/0000-0002-2784-1841

\section{References}

1. Raman RPC, Taiyeb-Ali TB, Chan SP, et al. Effect of nonsurgical periodontal therapy versus oral hygiene instructions on type 2 diabetes subjects with chronic periodontitis: a randomised clinical trial. BMC Oral Health 2014;14(1):1-10. DOI: 10.1186/1472-6831-14-79.

2. Katagiri $\mathrm{S}$, Nitta $\mathrm{H}$, Nagasawa $\mathrm{T}$, et al. Effect of glycemic control on periodontitis in type 2 diabetic patients with periodontal disease. J Diabetes Investig 2013;4(3):320-325. DOI: 10.1111/jdi.12026.

3. Munjal A, Jain $Y$, Kote $S$, et al. A study on the change in $\mathrm{HbA1C}$ levels before and after non-surgical periodontal therapy in type-2 diabetes mellitus in generalized periodontitis. J Family Med Prim Care 2019;8(4):1326. DOI: 10.4103/jfmpc.jfmpc_105_19.

4. O'Connell PA, Taba Jr M, Nomizo A, et al. Effects of periodontal therapy on glycemic control and inflammatory markers. J Periodontol 2008;79(5):774-783. DOI: 10.1902/jop.2008.070250.

5. Teshome A, Yitayeh A. The effect of periodontal therapy on glycemic control and fasting plasma glucose level in type 2 diabetic patients: systematic review and meta-analysis. BMC Oral Health 2017;17(1):1-11. DOI: 10.1186/s12903-016-0249-1. 
6. Talakey AA, Hughes $F$, Almoharib $H$, et al. The added value of periodontal measurements for identification of diabetes among Saudi adults. J Periodontol 2021;92(1):62-71. DOI: 10.1002/JPER.20-0118.

7. Aranzazu-Moya GC, Hernández-Castañeda AA, Archila Antolinez LH. Effects of periodontal therapy with topical antibiotics in the glycemic control of diabetic patients: systematic review. Rev Estomatol 2019;27(1):31-42. DOI: 10.25100/re.v27i1.8735

8. Katagiri $\mathrm{S}$, Nitta $\mathrm{H}$, Nagasawa $\mathrm{T}$, et al. Multi-center intervention study on glycohemoglobin (HbA1c) and serum, high-sensitivity CRP (hsCRP) after local anti-infectious periodontal treatment in type 2 diabetic patients with periodontal disease. Diabetes Res Clin Pract 2009;83(3):308-315. DOI: 10.1016/j.diabres.2008.10.016.

9. Tsobgny-Tsague NF, Lontchi-Yimagou E, Nana ARN, et al. Effects of nonsurgical periodontal treatment on glycated hemoglobin on type 2 diabetes patients (PARODIA 1 study): a randomized controlled trial in a sub-Saharan Africa population. BMC Oral Health 2018;18(1): 1-8. DOI: 10.1186/s12903-018-0479-5.

10. Bharti $\mathrm{P}$, Katagiri $\mathrm{S}$, Nitta $\mathrm{H}$, et al. Periodontal treatment with topical antibiotics improves glycemic control in association with elevated serum adiponectin in patients with type 2 diabetes mellitus. Obes Res Clin Pract 2013;7(2):e129-e138. DOI: 10.1016/ j.orcp.2011.11.005.

11. Das AC, Das SJ, Panda S, et al. Adjunctive effect of doxycycline with conventional periodontal therapy on glycemic level for chronic periodontitis with type 2 diabetes mellitus subjects. J Contemp Dent Pract 2019;20(12):1417-1423. DOI: 10.5005/jp-journals-10024-2722. PMID: 32381843.

12. Macedo GO, Novaes AB, Souza SLS, et al. Additional effects of aPDT on nonsurgical periodontal treatment with doxycycline in type
II diabetes: a randomized, controlled clinical trial. Lasers Med Sci 2014;29(3):881-886. DOI: 10.1007/s10103-013-1285-6.

13. Al-Zahrani MS, Bamshmous SO, Alhassani AA, et al. Short-term effects of photodynamic therapy on periodontal status and glycemic contro of patients with diabetes. J Periodontol 2009;80(10):1568-1573. DOI: 10.1902/jop.2009.090206.

14. Singh S, Kumar V, Kumar S, et al. The effect of periodontal therapy on the improvement of glycaemic control in patients with type 2 diabetes mellitus: a randomized controlled clinical trial. Int J Diabetes Dev Ctries 2008;28(2):38-44. DOI: 10.4103/0973-3930.43097.

15. Rodrigues DC, Taba MJ, Novaes AB, et al. Effect of non-surgical periodontal therapy on glycemic control in patients with type 2 diabetes mellitus. J Periodontol 2003;74(9):1361-1367. DOI: 10.1902/ jop.2003.74.9.1361.

16. Grossi SG, Skrepcinski FB, DeCaro T, et al. Treatment of periodontal disease in diabetics reduces glycated hemoglobin. J Periodontol 1997;68:713-719. DOI: 10.1902/jop.1997.68.8.713.

17. Skaleric $U$, Schara $R$, Medvescek $M$, et al. Periodontal treatment by Arestin and its effects on glycemic control in type 1 diabetes patients. J Int Acad Periodontol 2004;6(4 Suppl.):160-165. PMID: 15536785. Available from: https://pubmed.ncbi.nlm.nih.gov/15536785/.

18. Simpson TC, Weldon JC, Worthington HV, et al. Treatment of periodontal disease for glycaemic control in people with diabetes mellitus. Cochrane Database Syst Rev 2015;(11):CD004714. DOI: 10.1002/14651858.CD004714.pub3.

19. Qureshi A, Bokhari SAH, Haque Z, et al. Clinical efficacy of SRP with and without metronidazole on glycemic control: three-arm randomized controlled trial. BMC Oral Health 2021;21(1):253. DOI: 10.1186/s12903021-01620-1. 